\title{
A novel primate model of delayed wound healing in diabetes: dysregulation of connective tissue growth factor
}

\author{
S. E. Thomson - S. V. McLennan • A. Hennessy • \\ P. Boughton • J. Bonner $\cdot$ H. Zoellner • D. K. Yue • \\ S. M. Twigg
}

Received: 7 July 2009 /Accepted: 22 October 2009/Published online: 29 November 2009

(C) Springer-Verlag 2009

\begin{abstract}
Aims/hypothesis Chronic non-healing wounds are a common complication of diabetes. Prolonged inflammation and decreased matrix accumulation may contribute. Connective tissue growth factor (CTGF) is induced during normal wound healing, but its regulation in diabetic wounds is unknown. We developed a primate model for the study of in vivo wound healing in baboons with long diabetes duration.

Methods Drum implants were placed subcutaneously into thighs of diabetic and non-diabetic control baboons. After 2 and 4 weeks the skin incision sites were removed for measurement of breaking strength and epithelial thickness.
\end{abstract}

Electronic supplementary material The online version of this article (doi:10.1007/s00125-009-1610-6) contains supplementary material, which is available to authorised users.

S. E. Thomson · S. V. McLennan · D. K. Yue $\cdot$ S. M. Twigg $(\bowtie)$ Discipline of Medicine, University of Sydney,

Camperdown,

Sydney, NSW, Australia

e-mail: stwigg@med.usyd.edu.au

S. E. Thomson • A. Hennessy

Department of Renal Medicine, Royal Prince Alfred Hospital,

Camperdown,

Sydney, NSW, Australia

\section{A. Hennessy}

School of Medicine, University of Western Sydney,

Camperdown,

Sydney, NSW, Australia

P. Boughton

St George Clinical School, St George Hospital,

Kogarah, NSW, Australia

P. Boughton

Department of Biomedical Engineering, University of Sydney,

Sydney, NSW, Australia
Drum implants were removed for analysis of granulation tissue and inflammatory cells, CTGF and tissue inhibitor of matrix metalloproteinase (TIMP-1). Degradation of added CTGF by wound fluid was also examined.

Results Healed incision site skin was stiffer (less elastic) in diabetic baboons and epithelial remodelling was slower compared with controls. Granulation tissue from diabetic baboons was reduced at 2 and 4 weeks, with increased vessel lumen areas at 4 weeks. Macrophages were reduced while neutrophils persisted in diabetic tissue. In diabetic wound tissue at 4 weeks there was less CTGF induced, as shown by immunohistochemistry, compared with controls. In contrast,

J. Bonner

Department of Endocrinology, Royal Prince Alfred Hospital,

Camperdown,

Sydney, NSW, Australia

H. Zoellner

Oral Pathology and Oral Medicine, Faculty of Dentistry,

University of Sydney,

Sydney, NSW, Australia

H. Zoellner

Westmead Centre for Oral Health, Westmead Hospital,

Sydney, NSW, Australia

S. V. McLennan • D. K. Yue $\cdot$ S. M. Twigg

Department of Endocrinology, University of Sydney,

Blackburn Building, DO6,

Sydney, NSW 2006, Australia 
immunoreactive fragments of CTGF were significantly increased in whole tissue lysate in diabetic baboons, suggesting that CTGF is redistributed in diabetes from granulation tissue into wound fluid. When recombinant human CTGF was co-incubated with wound fluid, increased CTGF degradation products were observed in both control and diabetic samples. Conclusions/interpretation This baboon model of wound healing reflects the abnormal microenvironment seen in human diabetic wounds and provides insights into the dysregulation of CTGF in diabetic wounds.

Keywords Animal C Complications · Cytokines ·

Non-human

$\begin{array}{ll}\text { Abbreviations } \\ \text { CTGF } & \text { Connective tissue growth factor } \\ \text { ECM } & \text { Extracellular matrix } \\ \text { GAPDH } & \text { Glyceraldehyde-3-phosphate dehydrogenase } \\ \text { MMP } & \text { Matrix metalloproteinase } \\ \text { PDGF } & \text { Platelet-derived growth factor } \\ \alpha \text {-SMA } & \alpha \text {-Smooth muscle actin } \\ \text { rhCTGF } & \text { Recombinant human connective tissue growth } \\ & \text { factor } \\ \text { TIMP-1 } & \text { Tissue inhibitor of matrix metalloproteinase } \\ \text { VEGF } & \text { Vascular endothelial growth factor }\end{array}$

\section{Introduction}

Diabetes is one of the leading causes of impaired wound healing, with many amputations performed each year as a result of chronic, non-healing wounds [1]. These wounds have been associated with prolonged and dysregulated levels of inflammatory cells, such as neutrophils and macrophages [2, 3]. Other studies have shown that the degradative capacity of chronic wounds is increased whilst growth factor levels are reduced [4, 5], collectively contributing to impaired granulation tissue formation and delayed epithelial closure in diabetic wounds.

For normal wound healing to progress, the balance between extracellular matrix (ECM) synthesis and its degradation is important, as is the induction of new blood vessels [5]. These processes are tightly regulated by growth factors such as platelet-derived growth factor (PDGF), vascular endothelial growth factor (VEGF) and connective tissue growth factor (CTGF) and by the matrix-degrading enzymes known as matrix metalloproteinases (MMPs). Compared with normal wound healing processes, wound healing in patients with diabetes results in decreased concentrations of PDGF and VEGF proteins in wound tissue [6,7]; however, the effect of diabetes on CTGF in wounds in skin and granulation tissue has not been studied.
CTGF is a profibrotic growth factor in the CCN family of proteins which is induced during normal cutaneous wound healing [8]. It has a variety of actions, including induction of fibroblast proliferation, migration, adhesion and ECM formation [8]. CTGF is also produced by cultured endothelial cells [9] and causes proliferation, migration and adhesion of vascular endothelial cells [10, 11]. We have previously shown, albeit in renal mesenchymal cells, that CTGF can upregulate levels of the specific MMP inhibitor TIMP-1 [12].

Wound healing models using implantation of subcutaneous devices have been developed in a variety of animals, including rats, dogs and humans [13-15]. These models allow the collection of cells, fluid and wound tissue, although typically they have only been short-term, from days up to a couple of weeks. The most common collection device has been the sponge $[13,14,16]$, where cells invade and lay down collagen. Other studies have involved insertion of porous cylinders, most commonly the HuntSchilling stainless steel mesh cylinder [17]. These cylinders have been useful for the study of wound repair as they induce a response that exhibits the classic phases of inflammation, connective tissue infiltration, neovascularisation and matrix deposition [15, 18]. Temporal changes in inflammatory cell infiltration, matrix deposition and growth factor production can also be measured.

We have previously reported changes due to diabetes complications in our established non-human primate model of type 1 diabetes [19-21]. This animal model of streptozotocin-induced diabetes has been well characterised $[22,23]$ and develops complications comparable with those occurring in human diabetes [19, 21]. Animals have diabetes duration of greater than 10 years. In the present work we examined the effects of diabetes on wound healing in these primates for the first time, by implanting sterile plastic drums subcutaneously. This novel wound model allows the collection of granulation tissue and wound fluid from these drums in the absence of external contamination. Epithelial changes and tensile strength of the healed incision site can also be assessed by excising the skin at the time of removal of the subcutaneous drums. We hypothesised that, compared with the age-matched cohort of non-diabetes controls, diabetic animals would show abnormal regulation of: cutaneous healing, inflammatory cell profiles, granulation tissue formation and tissue CTGF.

\section{Methods}

Baboon model

The induction and maintenance of this colony of long-term diabetic and control baboons has been described elsewhere 
[22]. Briefly, male baboons were made diabetic at 2.5 years of age by intravenous injection of streptozotocin (65 $\mathrm{mg} / \mathrm{kg}$ in $0.1 \mathrm{~mol} / 1$ citrate buffer, $\mathrm{pH} 4.5)$. Animals were maintained on once daily injections of a combination of short- and long-acting insulin (Humulin $\mathrm{R}$ and Humulin NPH; Eli Lilly, West Ryde, NSW, Australia) at an average dose of $4 \mathrm{U} / \mathrm{kg} /$ day with adjustments made at intervals of 3 months according to the $\mathrm{HbA}_{1 \mathrm{c}}$ level. Animal details at the time of the study are shown in Table 1. All work was approved by the Sydney South West Area Health Service Animal Ethics Committee under the guidelines of National Health and Medical Research Council of Australia for use of non-human primates in research.

To implant and remove drums, baboons were anaesthetised using a combination of ketamine $(6 \mathrm{mg} / \mathrm{kg}$; Ketamil; Troy Laboratories, Smithfield, NSW, Australia) and medetomidine hydrochloride (60 $\mu \mathrm{g} / \mathrm{kg}$; Domitor; Novartis Animal Health, North Ryde, NSW, Australia). Effects of medetomidine were reversed by atipamezole hydrochloride $(300 \mu \mathrm{g} / \mathrm{kg}$; Antisedan; Novartis Animal Health, Australia).

Drum implants (Fig. 1a) were $5 \times 15 \mathrm{~mm}$ (depth $\times$ diameter) polystyrene Netwells with fine polyester $74 \mu \mathrm{m}$ mesh on the top and bottom surfaces (Corning Life Sciences, Santa Clara, CA, USA). Implants were plasmasterilised and inserted surgically, two drums per thigh via a $3 \mathrm{~cm}$ skin incision. Incisions (Fig. 1b) were closed using subcuticular absorbable sutures (Polysorb; Tyco Healthcare, Norwalk, CT, USA). Antibiotic cover was provided by an injection of amoxicillin trihydrate on alternate days (10 mg/kg; Betamox LA; Norbrook Laboratories, Tullamarine, VIC, Australia), three in total. After 2 and 4 weeks, the healed, sutured skin incision site was excised with $10 \mathrm{~mm}$ skin margins, and stored at $-80^{\circ} \mathrm{C}$ for later measurement of wound breaking strength and the thickness of the epithelial incision site. By the time of skin excision, all incision sites had healed in all animals. Drums ( $n=2$ per time point) were then removed and wound fluid was aspirated from within the chamber for later analysis. The granulation tissue from within the drum was divided and fixed in 10\% formalin for histological analysis or snap-frozen for later analysis.
Incision site analysis

For the measurement of wound breaking strength, healed sutured skin incision sites were removed from storage and cut into shape using an aluminium template (Fig. 1c). Width, length and thickness of skin pieces were measured using callipers. Tensile strength was determined at room temperature. Tissue ends were placed in the jaws of an Elf 3400 Tensiometer (BOSE EnduraTec, Minnetonka, MN, USA). Load and displacement until the time of skin rupture at the healed incision site were obtained using a $45 \mathrm{~N}$ load at a cross-head speed of $10 \mathrm{~mm} / \mathrm{min}$. Cross-sectional area was determined from original skin thickness measurements and values were used to calculate stress and strain and Young's modulus (tensile strength).

As a marker of remodelling, the epidermal thickness of the healed incision site was measured in sections stained with haematoxylin and eosin (Image J; National Institutes of Health, Bethesda, MD, USA), at five regular points along the suture line of the healed epidermis and at five points in unwounded skin. Values were averaged and results expressed as the percentage increase compared with unwounded skin.

\section{Histopathology and immunohistochemistry}

Formalin-fixed paraffin-embedded sections $(5 \mu \mathrm{m})$ were stained with haematoxylin and eosin for examination of granulation tissue appearance and Masson's trichrome for calculation of the amount of granulation tissue. Analysis for numbers of neutrophils (1:500; Cat. no. 144499, Abcam, Cambridge, UK) and macrophages (1:800; Cat. no. MCA874G, Serotec Kidlington, Oxford, UK), blood vessel size (1:200 CD31, Chemicon International, Temecula, CA, USA), collagen IV (1:400; Cat. no. 6311, Abcam), fibronectin (1:150; Cat. no. 341645, Calbiochem, Los Angeles, CA, USA), $\alpha$-smooth muscle actin ( $\alpha$-SMA) (1:200; Cat. no. 5694, Abcam), glyceraldehyde-3-phosphate dehydrogenase (GAPDH; Cat. no. 8245, Abcam), CTGF (1:400; inhouse antiserum 196 and 197, each directed against the same carboxy-terminal antigenic site of CTGF, as described previously [24]) and TIMP-1 (1:400; Cat. no. 770, Chemicon International) was by immunohistochemistry using the

Table 1 Baboon characteristics at the time of the study

\begin{tabular}{|c|c|c|c|c|c|c|c|c|c|c|}
\hline \multirow[t]{2}{*}{ Group } & \multicolumn{2}{|l|}{ Age (years) } & \multicolumn{2}{|c|}{$\begin{array}{l}\text { Diabetes duration } \\
\text { (years) }\end{array}$} & \multicolumn{2}{|l|}{ Weight (kg) } & \multicolumn{2}{|c|}{$\begin{array}{l}\text { Blood glucose } \\
(\mathrm{mmol} / \mathrm{l})\end{array}$} & \multicolumn{2}{|l|}{$\mathrm{HbA}_{1 \mathrm{c}}(\%)$} \\
\hline & Mean \pm SD & Range & Mean \pm SD & Range & Mean \pm SD & Range & Mean \pm SD & Range & Mean \pm SD & Range \\
\hline Control $(n=6)$ & $13.4 \pm 0.9$ & $11.9-14.3$ & - & & $24.0 \pm 1.1$ & $22.9-25.0$ & $4.3 \pm 0.5$ & $3.9-5.2$ & $3.9 \pm 0.4$ & $3.3-4.3$ \\
\hline Diabetic $(n=7)$ & $13.8 \pm 0.81$ & $12.8-14.9$ & $11.3 \pm 0.81$ & $10.3-12.4$ & $19.3 \pm 1.9$ & $16.3-22.0$ & $29.9 \pm 6.3$ & $22.5-39.7$ & $8.9 \pm 1.0$ & $7.9-10.7$ \\
\hline
\end{tabular}



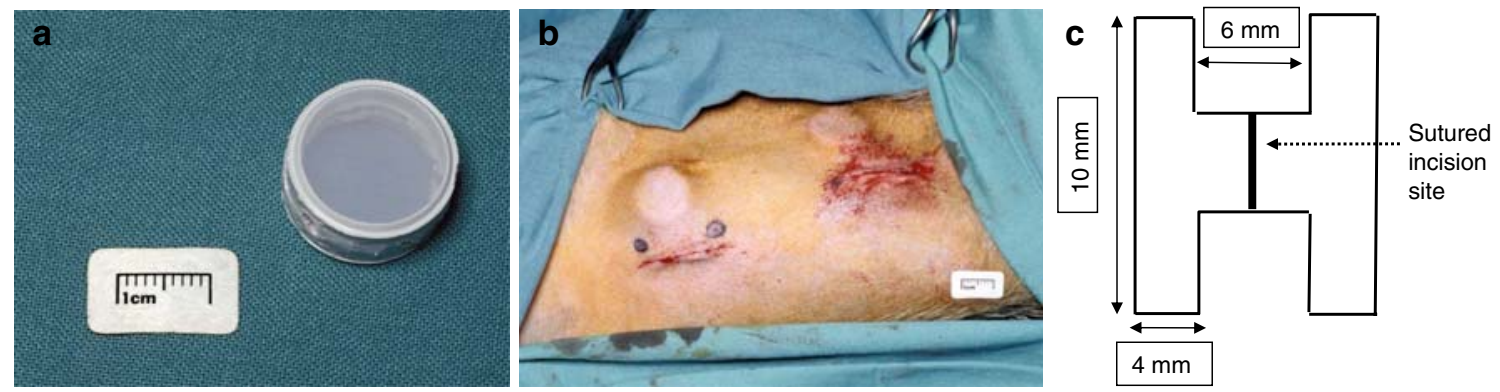

Fig. 1 The baboon model and drum implant. a Drum implant used for tissue collection. b Drum implants in situ after surgical insertion. c $\mathrm{H}$-shaped template used to excise skin of standard dimensions and containing the healed cutaneous incision site at 2 or 4 weeks

$\mathrm{ABC}$ method (Vectastain ABC Kit; Vector Laboratories, Burlingame, CA, USA) as reported previously [21]. To further assess the results of granulation tissue CTGF immunohistochemistry, a completely different primary anti-CTGF antibody (XY-1) was used in place of antiCTGF 196 antibody. XY-1 was generated in New Zealand White rabbits (Chiron Mimotopes, Melbourne, VIC, Australia) against full-length recombinant human CTGF (rhCTGF) protein [25] and the resulting antiserum was confirmed using a previously described method [21] to specifically detect CTGF in baboon renal tissue by immunohistochemistry (not shown).

\section{Quantification of staining}

Sections stained with Masson's trichrome were examined microscopically and amounts of granulation tissue present were determined using Image Pro Plus (Media Cybernetics, Silver Spring, MD, USA). The amount of granulation tissue was expressed as a percentage of total tissue area obtained from three sections $50 \mu \mathrm{m}$ apart. Sections stained for CTGF, TIMP-1, fibronectin and collagen IV were scored from 0 to 3 by two independent observers blinded to tissue source, 0 indicating no staining and 3 intense staining. Macrophages and neutrophils were counted at $\times 100$ magnification in 20 fields using two sections $50 \mu \mathrm{m}$ apart and results were averaged. Lumen areas of blood vessels were measured at $\times 20$ magnification using Axiovision 4 (Carl Zeiss Vision). All vessel lumens in three separate sections per animal were measured.

Tissue RNA isolation and real-time quantitative PCR

Pure total RNA was isolated freshly from wound tissue $(\sim 100 \mathrm{mg})$ and prepared as cDNA, as described previously $[12,24]$. Primers were designed against highly conserved regions of multiple species including $>99 \%$ homology with human amplicons. Primer sequences are shown in the Electronic supplementary material (ESM) Table 1. Thermal cycles for amplification were as follows: $2 \mathrm{~min}$ at $50^{\circ} \mathrm{C}$, $5 \mathrm{~min}$ at $95^{\circ} \mathrm{C}$ and 45 cycles of $95^{\circ} \mathrm{C}$ for $10 \mathrm{~s}, 55^{\circ} \mathrm{C}$ for $20 \mathrm{~s}$ and $72^{\circ} \mathrm{C}$ for $20 \mathrm{~s}$. The delta/delta method was used to compare gene expression between animals with diabetes and non-diabetic controls. Results were corrected for $36 B 4$ (also known as $R P L P O$ ) as housekeeper.

Analysis of whole wound tissue

CTGF protein was extracted from wound tissue using RIPA buffer. Whole tissue lysate was loaded (50 $\mu \mathrm{g}$ per lane) onto SDS-PAGE gels under reducing conditions then transferred onto polyvinylidene fluoride membranes and assessed by western immunoblotting using anti-CTGF primary antibody $(197,1: 1,000)$ as described previously [26]. Immunoreactive band intensities were assessed by Image Analysis, corrected for the housekeeper loading control, GAPDH.

\section{Degradation of rhCTGF by wound fluid}

Wound fluid samples ( $5 \mu$ from each baboon) were pooled into control and diabetic groups. The rhCTGF was produced as described previously [12, 26]. Pooled wound fluid $(15 \mu \mathrm{l})$ was mixed with either PBS $(15 \mu \mathrm{l})$ or rhCTGF $(15 \mu \mathrm{l}$ ), each containing $0.1 \%$ BSA (Sigma). In other samples, rhCTGF $(15 \mu \mathrm{l})$ alone was incubated with PBS containing $0.1 \%$ BSA $(15 \mu \mathrm{l})$. All samples (total $30 \mu \mathrm{l}$ ), except one rhCTGF sample, as indicated in Fig. 8b, were incubated at $37^{\circ} \mathrm{C}$ for $24 \mathrm{~h}$ and then loaded onto a SDSPAGE gradient gel. The effect of wound fluid on rhCTGF degradation was analysed by western immunoblotting against CTGF using 197 antibody [25]. Total immunoreactivity was determined by Image Analysis and expressed as individual molecular mass band intensities and the sum of all immunoreactive bands.

\section{Statistical analysis}

Differences between groups were analysed by ANOVA using NCSS (Number Cruncher Statistical Analysis, UT, USA), except for blood vessel lumen size, for which differences between the groups were analysed using a two-sample $t$ test 
assuming equal variance. All data are mean $\pm \mathrm{SD}$ and values of $p<0.05$ were considered significant.

\section{Results}

Animal characteristics

Physical characteristics of the baboons at the time of tissue sampling are shown in Table 1. The diabetic baboons had lower body weight, higher $\mathrm{HbA}_{1 \mathrm{c}}$ and higher blood glucose levels than control animals and their diabetes duration was more than 10 years.

Effect of diabetes on the wound breaking strength and incision site epidermal thickness

Young's modulus was greater in the diabetic baboons compared with the control baboons (Table 2, $p<0.05$ ), indicating the healed incision site was stiffer and less extendable in the diabetic baboons. In control animals the epidermal thickness at the incision site was significantly greater at 2 weeks than 4 weeks. In contrast, this decrease in thickness with time was not observed in the diabetic animals, in which the thickness was significantly greater than in controls at 4 weeks (Fig. 2, Table 2).

Effect of diabetes on granulation tissue formation, inflammatory cell response, CTGF and TIMP-1 immunostaining

Formation of granulation tissue After 4 weeks there was less granulation tissue in the drums of the diabetic baboons compared with controls (Fig. 3a-d, quantified in Fig. 4a). Under H\&E staining at higher magnification the tissue also appeared coarser, less well formed and more disorganised in diabetic animals than in controls (Fig. 3e-h). Fibronectin and collagen IV staining appeared darker in control than diabetic tissue, as seen at 4 weeks (Fig. 3i, j and k, 1 respectively). There was a trend for fewer blood vessels in diabetic tissue (Fig. 4b). Blood vessel lumens at 4 weeks were significantly larger (control $610 \pm 218$ pixels, diabetic, $1263 \pm 389$ pixels; $p=0.01$ ), and the vessel walls appeared to be thinner (Fig. 4c, d) in tissue from the diabetic baboons. The $\alpha$-SMA staining in control and diabetic animals was mainly localised to endothelial cells rather than fibroblasts (Fig. 4e, f).

Pattern of inflammatory cell response The pattern of change in inflammatory cell infiltrate appeared to be different between the groups. In control animals the neutrophil and macrophage numbers decreased between the 2- and 4-week time points (Fig. 5a and b respectively). This decrease was not observed in the diabetic animals and the macrophage number at 2 weeks was lower than in controls at the same time point $(p<0.05)$ (Fig. 5b).

CTGF and TIMP-1 detection By immunohistochemistry, the amount of CTGF protein was greater in control tissue compared with diabetic tissue at both 2 and 4 weeks, the difference reaching significance at 4 weeks (Figs 6a-d and 7a) $(p<0.05)$. The same overall trend was observed with $\mathrm{XY}-1$ anti-CTGF antibody (staining score, mean \pm SD: control, 2 weeks, $2.17 \pm 1.04$, diabetic, 2 weeks, $1.69 \pm$ 0.31; control, 4 weeks, $2.40 \pm 0.38$, diabetic, 4 weeks, $1.92 \pm$ 0.75; not significant). (See Electronic supplementary material [ESM] Fig. 1). A similar pattern was observed for TIMP-1 protein levels, differences failing to reach statistical significance (Figs $6 \mathrm{e}-\mathrm{h}$ and $7 \mathrm{~b}$ ). There was no difference in CTGF mRNA levels in the tissue (Fig. 7a), suggesting post-transcriptional regulation and the possible compartmentalisation of CTGF across wound tissue and fluid. The TIMP-1 (also known as TIMP1) mRNA levels were also not different between groups (Fig. 7d). Interestingly, reduced macrophage number at 2 weeks in diabetic tissue correlated positively with a low level of wound tissue CTGF protein at 4 weeks $(r=0.65, p<0.05)$.

Table 2 Analysis of the healed incision site

\begin{tabular}{llccc}
\hline Time point & $\begin{array}{l}\text { Young's } \\
\text { modulus }\left(\mathrm{N} / \mathrm{m}^{2}\right)\end{array}$ & $\begin{array}{l}\text { Epidermal thickness } \\
\text { at incision site }(\mathrm{mm})\end{array}$ & $\begin{array}{l}\text { Epidermal thickness of } \\
\text { unwounded skin }(\mathrm{mm})\end{array}$ & $\begin{array}{c}\text { Epidermal thickness (increase } \\
\text { compared with unwounded skin) }(\%)\end{array}$ \\
\hline $\begin{array}{l}\text { Control group } \\
2 \text { weeks }\end{array}$ & $0.51 \pm 0.16$ & $0.139 \pm 0.024$ & $0.052 \pm 0.016$ & 269 \\
4 weeks & $1.35 \pm 0.42^{*}$ & $0.085 \pm 0.014^{*}$ & $0.054 \pm 0.008$ & 158 \\
$\begin{array}{l}\text { Diabetic group } \\
2 \text { weeks }\end{array}$ & $0.64 \pm 0.24$ & $0.133 \pm 0.024$ & $0.049 \pm 0.012$ & 273 \\
4 weeks & $2.04 \pm 0.21^{\dagger}$ & $0.130 \pm 0.040^{\dagger}$ & $0.056 \pm 0.049$ & 232 \\
\hline
\end{tabular}

Results are mean \pm SD

${ }^{*} p<0.05$ vs data for 2 weeks in the same group; ${ }^{\dagger} p<0.05$ vs control at same time point (ANOVA) 

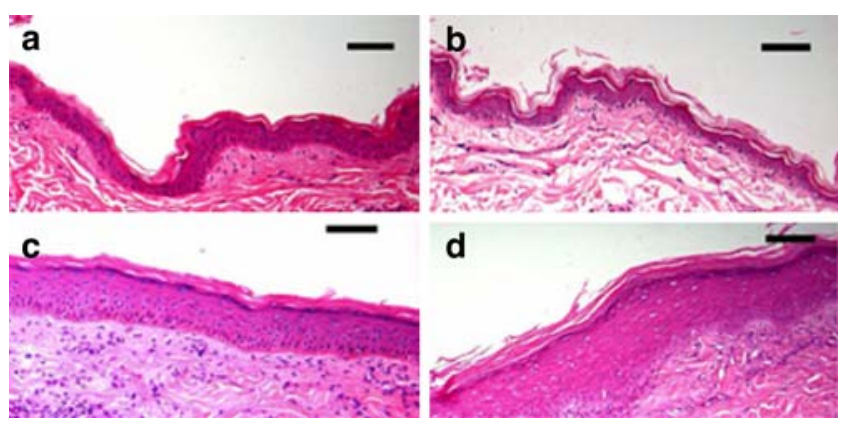

Fig. 2 Representative images of the epidermis in unwounded skin in control (a) and diabetic (b) baboons. Skin at the healed incision site in control (c) and diabetic (d) baboons, each at 4 weeks. Epidermal thickness at the site of the healed incision site in the diabetic baboons was significantly greater than that in the control baboons (Table 2; $p<0.05$ ). Magnification $\times 10$; scale bar, $100 \mu \mathrm{m}$

As a reference, CTGF immunoperoxidase staining in control and diabetic skin from unwounded baboons is shown in ESM Fig. 2, indicating minimal CTGF signal in hair follicles and basal epidermal cells and only weak staining in the unwounded dermal tissue. There were no clear differences between control and diabetic baboons in unwounded skin.
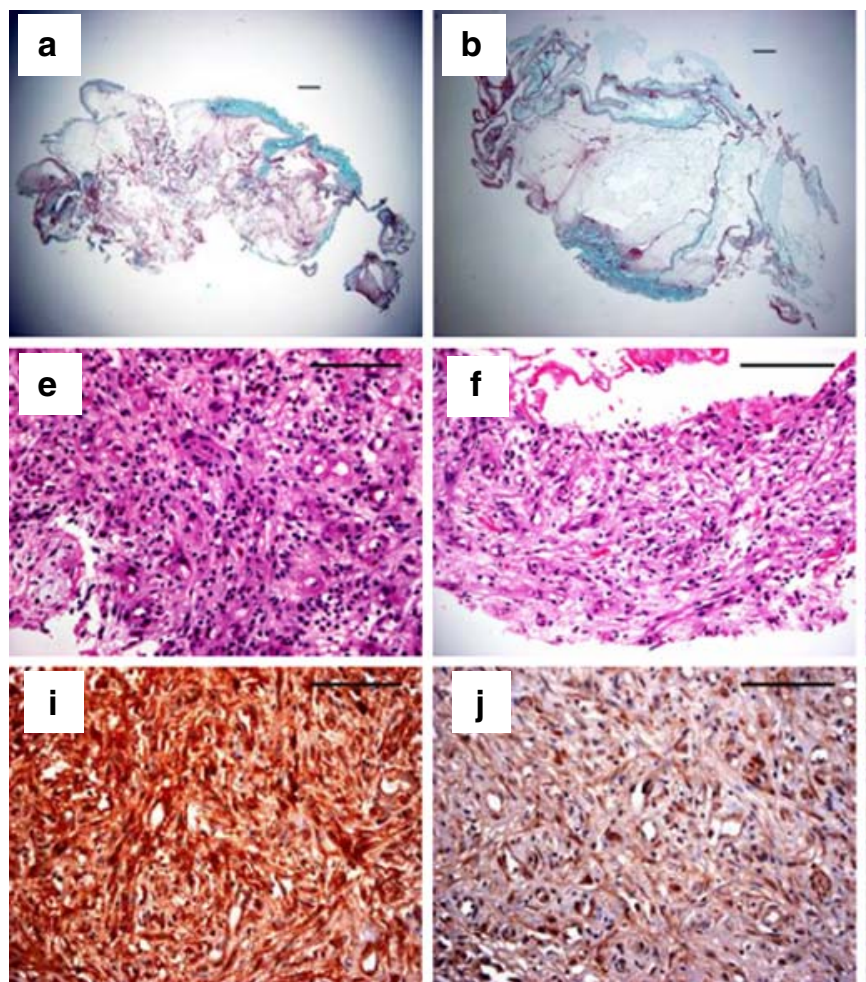

Fig. 3 Histological appearance of drum granulation tissue. Representative images showing Masson's trichrome stain (a-d) of complete drum tissue removed from control $(\mathbf{a}, \mathbf{c})$ and diabetic baboons $(\mathbf{b}, \mathbf{d})$ at 2 weeks $(\mathbf{a}, \mathbf{b})$ and 4 weeks $(\mathbf{c}, \mathbf{d})$. Magnification $\times 2$; scale bar, $100 \mu \mathrm{m}$. An increased amount of granulation tissue (shown in blue) is seen in control animals at 4 weeks compared with control at 2 weeks. Haematoxylin and eosin stain $(\mathbf{e}-\mathbf{g})$ of tissue from control $(\mathbf{e}, \mathbf{g})$ and
The effect of diabetes on CTGF levels in whole tissue lysate was investigated by western immunoblotting. The relative amount of $\sim 26 \mathrm{kDa}$ CTGF protein fragment in tissue from the diabetic baboons at 4 weeks was significantly greater than that in control tissue (Fig. 8a, Table 3). The same immunoblot profile seen for the 197 primary antiCTGF antibody was observed using the 196 anti-CTGF antibody (not shown). When combined with the CTGF immunohistochemistry result, these whole tissue lysate data suggest that in diabetic animals CTGF may be redistributed from granulation tissue into other sites, including wound fluid.

To determine whether wound fluid from diabetic animals may be more likely to degrade exogenously added CTGF, pooled wound fluids from control and diabetic baboons were incubated with rhCTGF and the effect on the amount of CTGF and its disappearance was examined by western immunoblotting (Fig. 8b). For analysis, the band intensities were measured and summed (Table 4). Incubation of rhCTGF with wound fluid collected from control and diabetic baboons at 2 weeks resulted in $\sim 40 \%$ and $45 \%$ reduction in total immunoreactivity, respectively. A different pattern was observed in pooled wound fluids obtained
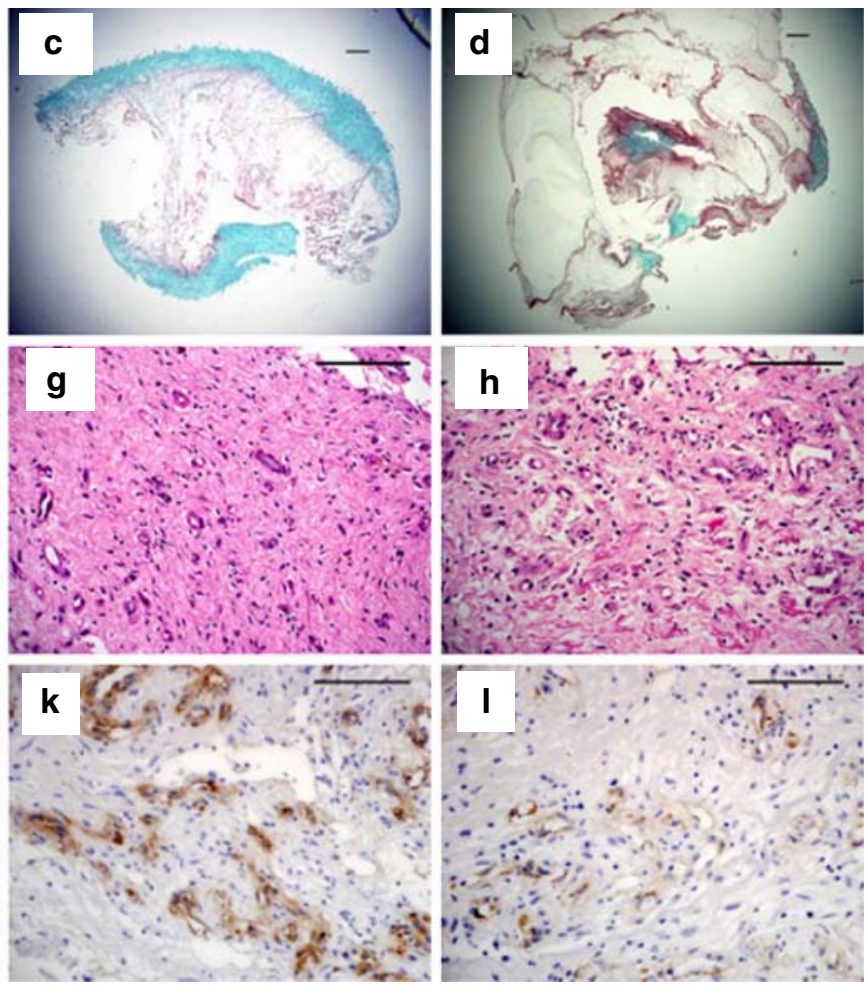

diabetic baboons (f, h) at 2 weeks $(\mathbf{e}, \mathbf{f})$ and 4 weeks $(\mathbf{g}, \mathbf{h})$. The diabetic tissue appeared looser, less well formed and less organised than control tissue. Fibronectin staining (i, j) of tissue from control (i) and diabetic (j) baboons at 4 weeks. Collagen IV staining $(\mathbf{k}, \mathbf{l})$ of tissue from control (k) and diabetic (l) baboon tissue at 4 weeks. Unless otherwise stated, magnification is $\times 40$; scale bar, $100 \mu \mathrm{m}$ 


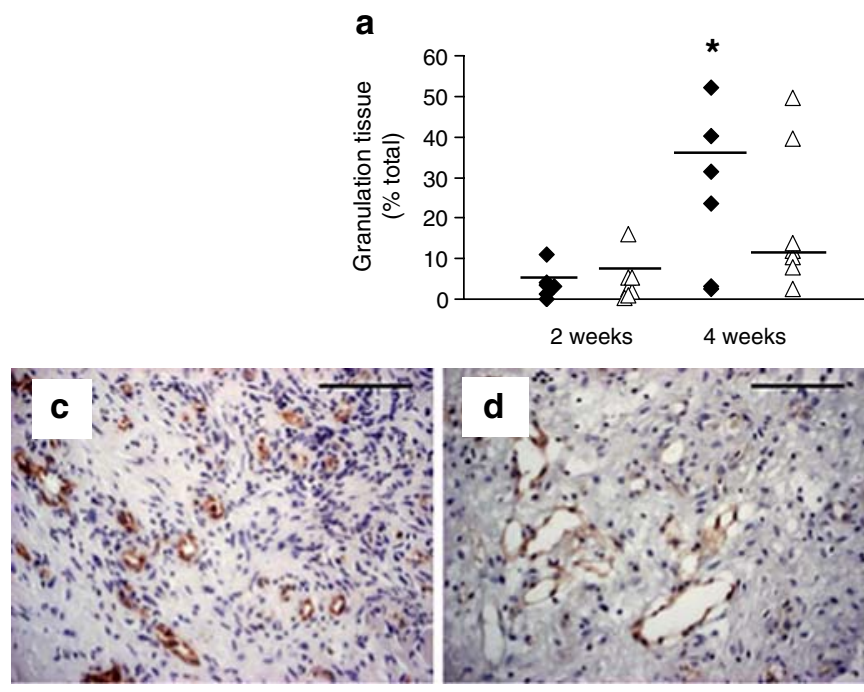

Fig. 4 Quantification of granulation tissue and blood vessels. (a) Relative amount of granulation tissue. Granulation tissue area as a percentage of the whole tissue area was increased in control baboons at 4 weeks compared with control at 2 weeks $\left({ }^{*} p<0.05\right)$. Control animal data are shown as black diamonds and diabetic animal data as white triangles. (b) Blood vessel density as blood vessel number per area of section tended to be increased in the control tissue compared with the diabetic tissue at 4 weeks but this difference did not reach statistical significance. Control animal data are shown as black
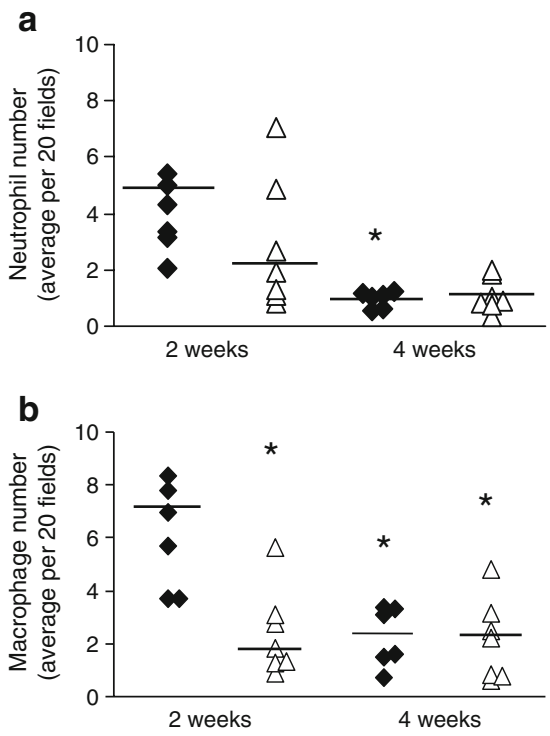

Fig. 5 Changes in inflammatory cell infiltrate. Control animal data are shown as black diamonds and diabetic animal data as white triangles. a Neutrophil number in control tissue had decreased significantly at 4 weeks compared with 2 weeks $\left({ }^{*} p<0.05\right)$. Diabetic tissue had a non-significant trend to fewer neutrophils at 2 weeks compared with controls at 2 weeks. b Macrophage number was markedly increased in the control tissue at 2 weeks compared with diabetic tissue at 2 weeks $\left({ }^{*} p<0.05\right)$. Macrophage number at 4 weeks was significantly reduced in control tissue compared with control tissue at 2 weeks $\left({ }^{*} p<0.05\right)$, whereas the level did not change in diabetic tissue at 4 weeks, compared with control tissue at 2 weeks. Thus, in diabetic tissue there was no peak influx of neutrophils or macrophages at either time point
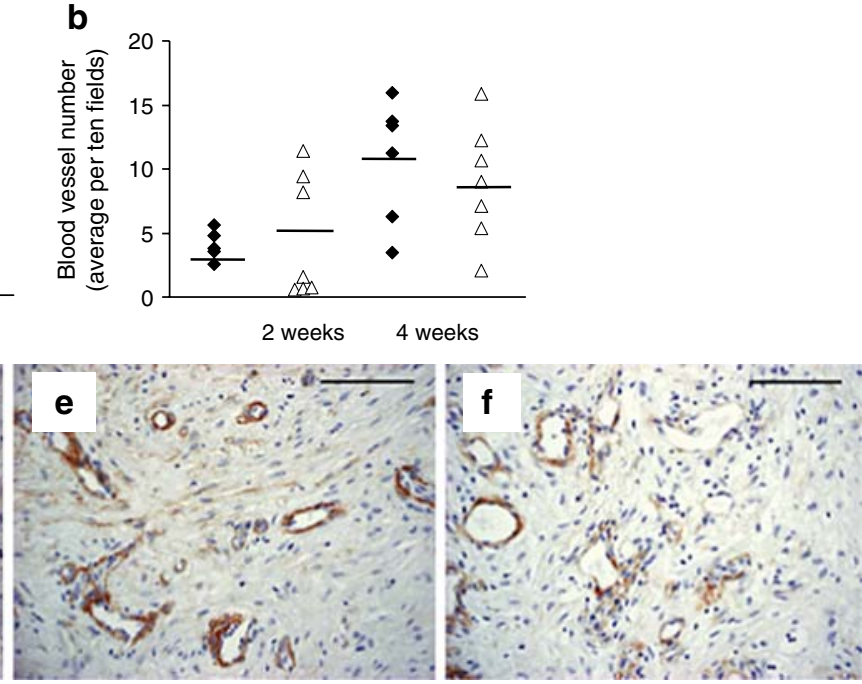

diamonds and diabetic animal data as white triangles. Blood vessel appearance after CD31 staining in control wound tissue (c) and diabetic wound tissue (d) at 4 weeks. Vessels in diabetic wound tissue had significantly larger lumens than those in control tissue (see text; $p=0.01$ ). Representative $\alpha$-SMA staining of control tissue (e) and diabetic tissue (f) at 4 weeks. $\alpha$-SMA staining in both control and diabetic tissue was mainly at endothelial cell sites rather than in interstitial fibroblasts. Magnification $\times 40$; scale bar, $100 \mu \mathrm{m}$

at 4 weeks, in that the total decrease in immunoreactivity was only $10 \%$ for control fluid and remained higher in fluids from diabetic baboons ( $30 \%$ loss). In particular, the lower molecular mass fragments $(\sim 17$ and $12 \mathrm{kDa})$ were reduced in intensity when rhCTGF was co-incubated with diabetic compared with control fluid. While this profile of change was also observed in a second independent experiment (not shown), statistically significant differences in relative CTGF fragment amounts in control and diabetic animals were not observed across both experiments combined (not shown).

\section{Discussion}

The novel findings of this study are that a wound healing model in diabetic baboons has been developed which demonstrates abnormalities in the wound microenvironment. Specifically, granulation tissue formation was reduced in diabetic animal wounds compared with wounds in control animals. In addition, for the first time in diabetic wounds, CTGF has been shown to be dysregulated. This subacute model with a duration of 4 weeks will be useful in testing methods to improve wound healing in diabetes.

Wound healing is a fibroproliferative response that aims to replace damaged or lost tissue. It is a complex phenomenon involving processes such as recruitment of inflammatory cells, proliferation and migration of parenchymal and connective tissue cells, then angiogenesis and 

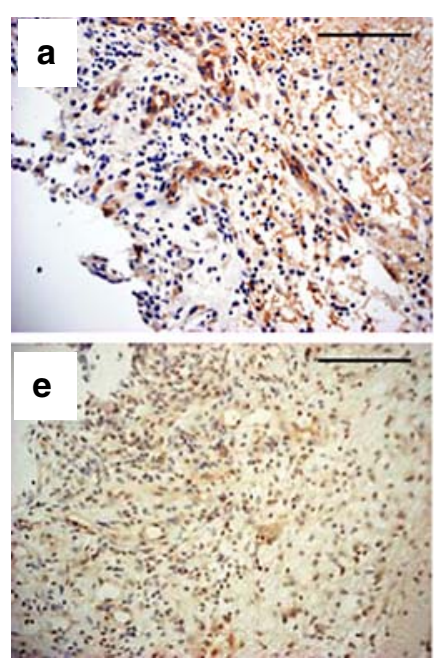

Fig. 6 Representative images of CTGF and TIMP-1 staining of granulation tissue using in-house CTGF antibody (196, 1:400 titre) and TIMP-1 antibody (Abcam AB770, 1:400), respectively. CTGF staining in a control baboon at 2 weeks (a) and 4 weeks (c) and a

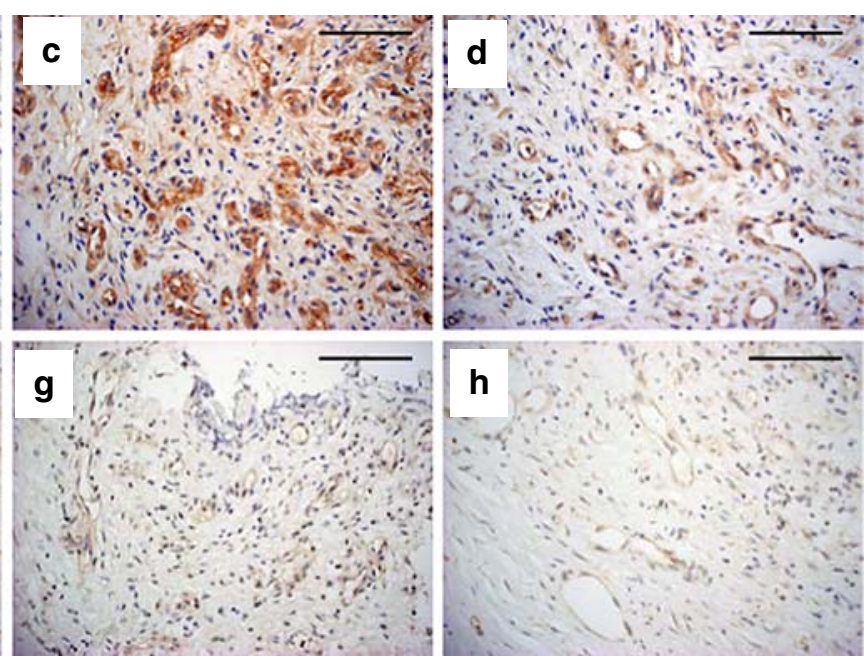

diabetic baboon at 2 weeks (b) and 4 weeks (d). TIMP-1 staining in a control baboon at (e) 2 weeks and (g) 4 weeks, and in a diabetic baboon at (f) 2 weeks and (h) 4 weeks. Magnification $\times 40$; scale bar, $100 \mu \mathrm{m}$

seen in human wounds. The baboon model of wound healing in this work is designed to enable analysis of both the epithelial changes that occur after an incisional injury to the skin, and to mimic the granulation tissue that typically forms during wound healing [15].

The main components of skin that affect its mechanical behaviour are elastin fibres, collagen fibres and the ground substance [31]. Pathological changes in the skin often correlate with changes in tissue elasticity [32]. The process of wound healing in the elderly is altered and delayed [33], and increasing age has been shown to result in increased skin stiffness [34]. In our baboon model we demonstrate a similar effect of increased stiffness in the diabetic healed skin incision site, which is likely to be due to increased cross-linking of skin collagen.

In the healing of cutaneous wounds, epidermal thickness initially increases above that seen in unwounded skin and
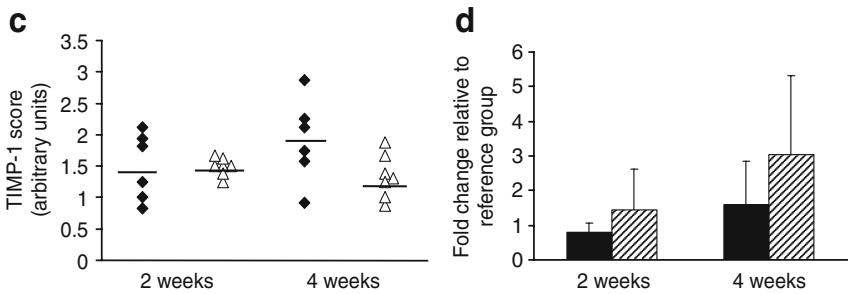

istry. There was no difference between animal groups in TIMP-1 protein at 2 or 4 weeks. d There was no difference between animal groups in TIMP-1 mRNA level at either time point. For the mRNA species measured, 36B4 was the reference housekeeper gene. In a and c, control animal data are shown as black diamonds and diabetic animal data as white triangles. In $\mathbf{b}$ and $\mathbf{d}$, control animal data are shown as black columns and diabetic animal data as shaded columns no difference between animal groups in the $C T G F$ mRNA level at either time point. c TIMP-1 protein determined by immunohistochem- 


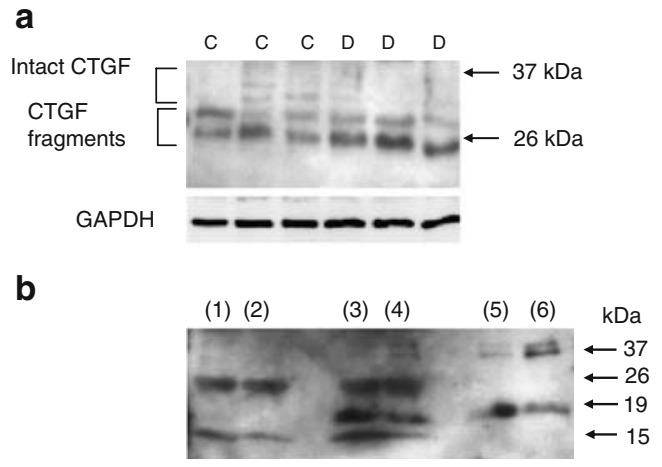

Fig. 8 a Representative anti-CTGF immunoblot of whole tissue lysates at 4 weeks, showing a profile of increased level of $\sim 26 \mathrm{kDa}$ CTGF fragment in diabetic tissue compared with control tissue, as reported in Table 3. Lower molecular mass fragments $(<26 \mathrm{kDa})$ were not regularly detected. C, control; D, diabetic. b Western immunoblot of CTGF fragments in pooled wound fluid after incubation of rhCTGF at $37^{\circ} \mathrm{C}$ for $24 \mathrm{~h}$. For sample volumes incubated, see Methods. Total CTGF band intensity was greater after rhCTGF incubation with pooled control fluid than after incubation with pooled diabetic fluid, although this difference did not reach statistical significance. Lane 1, control wound fluid $+0.1 \%$ albumin in PBS; lane 2, diabetic wound fluid $+0.1 \%$ albumin in PBS; lane 3, control wound fluid + rhCTGF; lane 4 , diabetic wound fluid + rhCTGF; lane 5 , rhCTGF $+0.1 \%$ albumin in PBS; lane 6, rhCTGF $+0.1 \%$ albumin in PBS (sample freshly prepared and not incubated)

then returns towards normal [30]. This was observed in the examination of the skin incision sites in the control animals at 2 then 4 weeks. The diabetic animals also showed an increase in epidermal thickness at 2 weeks, although the lack of reduction in thickness at 4 weeks suggests that epidermal wound healing is delayed in diabetic animals.

The wound microenvironment in diabetes is altered in many ways, including abnormal cellular infiltration and impaired vascular formation [35]. There is delayed and prolonged inflammation with impaired angiogenesis [36], as well as defective macrophage function and decreased collagen synthesis [35]. Neutrophil infiltration appears to be delayed and protracted in diabetes, while the role of the macrophage in the transition from the inflammatory to the proliferating phase of a healing wound is impaired [5]. Our model displays these findings with a delayed influx of both neutrophils and macrophages and reduced granulation tissue. The increase in vessel lumen size, approximately twofold, in diabetic tissue at 4 weeks was a striking and novel finding, as was the observed reduction in vessel wall thickness. The functional significance of this is not clear and further studies are required to assess vessel dysfunction, including leakiness.

Because of their early arrival at the wound site and phagocytosis of bacteria and removal of tissue debris, neutrophils are considered to have a role confined to host defence [37]. It is recognised that inflammatory cells are essential for normal wound healing; neutrophil-deficient mice demonstrate impaired wound healing [38]. One advantage of this baboon model is the absence of infection, so the inflammatory cells present are part of the process of granulation tissue formation, not removal of bacteria. This inflammatory response is important but it must be regulated to prevent its activity from becoming excessive [39], as excessive inflammatory cells and mediators result in imbalances in wound proteases and their inhibitors, leading to inhibition of matrix synthesis and remodelling [40]. In this model, in the diabetic tissue neutrophil infiltrates did not decrease as consistently as observed in the control tissue 4 weeks after drum insertion.

Macrophages are important in wound healing as they secrete growth factors and cytokines that attract fibroblasts and endothelial cells as well as MMPs to remodel the granulation tissue [2, 41]. It is important that the macrophages present at the time release a growth factor that is required at that stage of healing, as this will vary throughout the course of the wound healing process [42]. In this study we show a marked reduction in macrophage infiltration into the site, an effect that was not corrected at the 4 week time point. Moreover, we found that the lack of macrophage infiltration at 2 weeks correlated with less tissue CTGF present by immunohistochemical staining at 4 weeks, suggesting a mechanistic link between the two processes, although intervention studies would be required to assess causality.

Table 3 CTGF protein in tissue lysate measured by western immunoblotting

\begin{tabular}{lllll}
\hline Band & Control (2 weeks) & Diabetic (2 weeks) & Control (4 weeks) & Diabetic (4 weeks) \\
\hline Intact CTGF & ND & ND & $0.27 \pm 0.10$ & $0.24 \pm 0.07$ \\
CTGF fragments & $0.68 \pm 0.20$ & $0.61 \pm 0.20$ & $0.64 \pm 0.10$ & $0.92 \pm 0.10^{*}$ \\
\hline
\end{tabular}

Data are given as arbitrary densitometric units

All results are divided by the internal standard to normalise between gels

$n=6$ animals per control group and $n=7$ animals per diabetic group

$\mathrm{ND}$, not detectable

${ }^{*} p<0.001$ different from control at same time point (paired $t$ test) 
Table 4 CTGF degradation after incubation at $37^{\circ} \mathrm{C}$ for $24 \mathrm{~h}$ with and without pooled wound fluid

\begin{tabular}{|c|c|c|c|c|c|}
\hline Band (kDa) & Control fluid + PBS & Diabetic fluid + PBS & Control fluid + CTGF & Diabetic fluid + CTGF & CTGF alone + PBS \\
\hline \multicolumn{6}{|l|}{2 weeks } \\
\hline 37 & & & 7,469 & 11,653 & 30,468 \\
\hline $24-26$ & 87,649 & 82,263 & 43,262 & 68,786 & \\
\hline 17 & & & 48,818 & 45,056 & 118,107 \\
\hline 12 & 64,037 & 50,969 & 83,881 & 31,087 & \\
\hline Total & 151,686 & 133,232 & 183,429 & 156,581 & 148,576 \\
\hline \multicolumn{6}{|l|}{4 weeks } \\
\hline 37 & & & 19,894 & 14,123 & 34,799 \\
\hline $24-26$ & 68,387 & 72,118 & 53,018 & 55,195 & \\
\hline 17 & & & 97,680 & 62,817 & 109,962 \\
\hline 12 & 70,718 & 57,407 & 81,283 & 62,966 & \\
\hline Total & 139,106 & 129,525 & 251,875 & 195,101 & 144,761 \\
\hline
\end{tabular}

Data are densitometric arbitrary units corrected for loading, as described in Methods

Early studies described the functions of CTGF as connective tissue cell proliferation, differentiation, chemotaxis and adhesion [8, 9, 43]. CTGF is synthesised by fibroblasts and stimulates the proliferation and chemotaxis of these cells as well as the production of various ECM components in fibroblast cultures, including collagen I, fibronectin and collagen IV [44, 45]. CTGF is produced at increased levels during normal wound repair [8] and at sites of fibrogenesis [11, 45]. CTGF is normally produced in keratinocytes in the epidermis [46], and in cell culture [47], so it may have a role in the remodelling of the epidermis after wounding. In a rhesus monkey model of burns, CTGF accelerated wound healing including epithelial closure [48]. CTGF is also a chemotactic factor for macrophages [49] and therefore it may also potentiate wound healing.

The new findings in the present work relating to CTGF demonstrate dysregulation in the presence of diabetes. Others have reported that in normal wound healing CTGF is induced [8], and we also found that CTGF was significantly increased in granulation tissue with time in the non-diabetic control animal wounds (Fig. 7a). In contrast, in unwounded skin CTGF levels were relatively low (ESM Fig. 2), also as reported by others [8]. In the present study, compared with granulation tissue from control animals, we observed a lesser amount of CTGF protein in the diabetic granulation tissue by immunohistochemistry at 4 weeks. In contrast, the carboxy-terminal $\sim 26 \mathrm{kDa}$ CTGF fragment was increased in whole tissue lysate from diabetic wounds. CTGF mRNA levels were not different between control and diabetic animal tissues. We also observed an overall reduction in the total amount of immunoreactive CTGF when exogenous rhCTGF was added to the pooled diabetic wound fluid after $24 \mathrm{~h}$ of incubation at $37^{\circ} \mathrm{C}$. This latter finding was not statistically significant and it may be that small sample size, pooled wound fluid and/or the limited incubation times studied may have contributed to detection of trends only. Collectively, these data suggest that CTGF is compartmentally changed post-translationally in diabetic tissue: it is lesser in amount in granulation tissue, and may be more readily released into and cleared from wound fluid. The determination of whether CTGF has a role in improving wound healing in diabetes studies would require CTGF therapy as protein and/or gene expression systems, probably as a local application.

In humans and animal models where it has been studied, steady-state $C T G F \mathrm{mRNA}$ and/or protein is upregulated in many diabetic tissues, as previously summarised [50]. We have found that CTGF is increased in kidney tissue in diabetic baboons and that the elevated renal CTGF protein levels predict subsequent pathological albuminuria [21]. In contrast, by using the same animals that were studied in the renal series, in the present work $C T G F$ mRNA was not increased in the diabetic wounds but CTGF protein was dysregulated at the posttranscriptional level. In diabetic wounds involving skin and subcutaneous tissues, growth factors, such as PDGF and VEGF protein, that are normally induced in solid organs in diabetes have been reported to be present in reduced amount in wounds $[6,7]$. The cause of the difference in growth factor findings across tissues in diabetes is unclear, although it may be due to the prolonged inflammatory and protease state that characterises diabetic wounds [39] compared with the profibrotic environment that predominates in diabetic nephropathy [21].

In summary, this model demonstrates that wound healing is delayed in diabetic baboons. Inflammatory cell induction is abnormal, granulation tissue is impaired and CTGF is not present in tissue in usual amounts. Interventions in the 
model can now be undertaken to determine whether wound healing in diabetes can be improved and possibly normalised.

Acknowledgements This work was supported by a project grant from the Juvenile Diabetes Foundation International and baboon colony support was provided by the Rebecca Cooper Foundation and the National Health and Medical Research Council of Australia.

Duality of interest The authors declare that there is no duality of interest associated with this manuscript.

\section{References}

1. Greenhalgh DG (2003) Wound healing and diabetes mellitus. Clin Plast Surg 30:37-45

2. Waugh HV, Sherratt JA (2006) Macrophage dynamics in diabetic wound dealing. Bull Math Biol 68:197-207

3. Goren I, Kampfer H, Podda M, Pfeilschifter J, Frank S (2003) Leptin and wound inflammation in diabetic ob/ob mice: differential regulation of neutrophil and macrophage influx and a potential role for the scab as a sink for inflammatory cells and mediators. Diabetes 52:2821-2832

4. Medina A, Scott PG, Ghahary A, Tredget EE (2005) Pathophysiology of chronic nonhealing wounds. J Burn Care Rehabil 26:306-319

5. Falanga V (2005) Wound healing and its impairment in the diabetic foot. Lancet 366:1736-1743

6. Keswani SG, Katz AB, Lim FY et al (2004) Adenoviral mediated gene transfer of PDGF-B enhances wound healing in type I and type II diabetic wounds. Wound Repair Regen 12:497-504

7. Lauer G, Sollberg S, Cole M et al (2000) Expression and proteolysis of vascular endothelial growth factor is increased in chronic wounds. J Invest Dermatol 115:12-18

8. Igarashi A, Okochi H, Bradham DM, Grotendorst GR (1993) Regulation of connective tissue growth factor gene expression in human skin fibroblasts and during wound repair. Mol Biol Cell 4:637-645

9. Bradham DM, Igarashi A, Potter RL, Grotendorst GR (1991) Connective tissue growth factor: a cysteine-rich mitogen secreted by human vascular endothelial cells is related to the SRC-induced immediate early gene product CEF-10. J Cell Biol 114:1285-1294

10. Shimo T, Nakanishi T, Kimura $Y$ et al (1998) Inhibition of endogenous expression of connective tissue growth factor by its antisense oligonucleotide and antisense RNA suppresses proliferation and migration of vascular endothelial cells. J Biochem (Tokyo) 124:130-140

11. Babic AM, Chen CC, Lau LF (1999) Fisp12/mouse connective tissue growth factor mediates endothelial cell adhesion and migration through integrin alphavbeta3, promotes endothelial cell survival, and induces angiogenesis in vivo. Mol Cell Biol 19:2958-2966

12. McLennan SV, Wang XY, Moreno V, Yue DK, Twigg SM (2004) Connective tissue growth factor mediates high glucose effects on matrix degradation through tissue inhibitor of matrix metalloproteinase type 1: implications for diabetic nephropathy. Endocrinology 145:5646-5655

13. Diegelmann RF, Lindblad WJ, Cohen IK (1986) A subcutaneous implant for wound healing studies in humans. J Surg Res 40:229237

14. Martson M, Viljanto J, Laippala P, Saukko P (1998) Connective tissue formation in subcutaneous cellulose sponge implants in the rat. The effect of the size and cellulose content of the implant. Eur Surg Res 30:419-425
15. Schilling JA, Joel W, Shurley HM (1959) Wound healing: a comparative study of the histochemical changes in granulation tissue contained in stainless steel wire mesh and polyvinyl sponge cylinders. Surgery 46:702-710

16. Broadley KN, Aquino AM, Hicks B et al (1989) The diabetic rat as an impaired wound healing model: stimulatory effects of transforming growth factor-beta and basic fibroblast growth factor. Biotechnol Ther 1:55-68

17. Grotendorst GR, Martin GR, Pencev D, Sodek J, Harvey AK (1985) Stimulation of granulation tissue formation by plateletderived growth factor in normal and diabetic rats. J Clin Invest 76:2323-2329

18. Hunt TK, Twomey P, Zederfeldt B, Dunphy JE (1967) Respiratory gas tensions and $\mathrm{pH}$ in healing wounds. Am J Surg 114:302-307

19. Birrell AM, Heffernan SJ, Kirwan P, McLennan S, Gillin AG, Yue DK (2002) The effects of aminoguanidine on renal changes in a baboon model of Type 1 diabetes. J Diabetes Its Complicat 16:301-309

20. Brooks BA, Heffernan S, Thomson S, McLennan SV, Twigg SM, Yue DK (2008) The effects of diabetes and aminoguanidine treatment on endothelial function in a primate model of type 1 diabetes. Am J Primatol 70:796-802

21. Thomson SE, McLennan SV, Kirwan PD et al (2008) Renal connective tissue growth factor correlates with glomerular basement membrane thickness and prospective albuminuria in a non-human primate model of diabetes: possible predictive marker for incipient diabetic nephropathy. J Diabetes Its Complicat 22:284-294

22. Heffernan S, Phippard A, Sinclair A et al (1995) A baboon (Papio hamadryas) model of insulin-dependent diabetes. J Med Primatol 24:29-34

23. Howard CF Jr (1982) Nonhuman primates as models for the study of human diabetes mellitus. Diabetes 31:37-42

24. Tikellis C, Cooper ME, Twigg SM, Burns WC, Tolcos M (2004) Connective tissue growth factor is up-regulated in the diabetic retina: amelioration by angiotensin-converting enzyme inhibition. Endocrinology 145:860-866

25. Twigg SM, Chen MM, Joly AH et al (2001) Advanced glycosylation end products up-regulate connective tissue growth factor (insulin-like growth factor-binding protein-related protein 2) in human fibroblasts: a potential mechanism for expansion of extracellular matrix in diabetes mellitus. Endocrinology 142:1760-1769

26. Twigg SM, Joly AH, Chen MM et al (2002) Connective tissue growth factor/IGF-binding protein-related protein-2 is a mediator in the induction of fibronectin by advanced glycosylation end-products in human dermal fibroblasts. Endocrinology 143:1260-1269

27. Martin P (1997) Wound healing-aiming for perfect skin regeneration. Science 276:75-81

28. Wang JF, Olson ME, Reno CR, Kulyk W, Wright JB, Hart DA (2000) Molecular and cell biology of skin wound healing in a pig model. Connect Tissue Res 41:195-211

29. Sullivan TP, Eaglstein WH, Davis SC, Mertz P (2001) The pig as a model for human wound healing. Wound Repair Regen 9:66-76

30. Greenhalgh DG (2005) Models of wound healing. J Burn Care Rehabil 26:293-305

31. Larrabee WF Jr (1986) A finite element model of skin deformation. I. Biomechanics of skin and soft tissue: a review. Laryngoscope 96:399-405

32. Tilleman TR, Tilleman MM, Neumann MH (2004) The elastic properties of cancerous skin: Poisson's ratio and Young's modulus. Isr Med Assoc J 6:753-755

33. Gosain A, DiPietro LA (2004) Aging and wound healing. World J Surg 28:321-326

34. Alexander H, Cook $T$ (2006) Variations with age in the mechanical properties of human skin in vivo. J Tissue Viab $16: 6-11$ 
35. Loots MA, Lamme EN, Zeegelaar J, Mekkes JR, Bos JD, Middelkoop E (1998) Differences in cellular infiltrate and extracellular matrix of chronic diabetic and venous ulcers vs acute wounds. J Invest Dermatol 111:850-857

36. da Costa Pinto FA, Malucelli BE (2002) Inflammatory infiltrate, VEGF and FGF-2 contents during corneal angiogenesis in STZdiabetic rats. Angiogenesis 5:67-74

37. Wetzler C, Kampfer H, Stallmeyer B, Pfeilschifter J, Frank S (2000) Large and sustained induction of chemokines during impaired wound healing in the genetically diabetic mouse: prolonged persistence of neutrophils and macrophages during the late phase of repair. J Invest Dermatol 115:245-253

38. Hubner G, Brauchle M, Smola H, Madlener M, Fassler R, Werner S (1996) Differential regulation of pro-inflammatory cytokines during wound healing in normal and glucocorticoid-treated mice. Cytokine 8:548-556

39. Pierce GF (2001) Inflammation in nonhealing diabetic wounds: the space-time continuum does matter. Am J Pathol 159:399-403

40. Parks WC (1999) Matrix metalloproteinases in repair. Wound Repair Regen 7:423-432

41. Singer AJ, Clark RA (1999) Cutaneous wound healing. N Engl J Med 341:738-746

42. Robson MC (1997) The role of growth factors in the healing of chronic wounds. Wound Repair Regen 5:12-17

43. Grotendorst GR (1997) Connective tissue growth factor: a mediator of TGF-beta action on fibroblasts. Cytokine Growth Factor Rev 8:171-179
44. Frazier K, Williams S, Kothapalli D, Klapper H, Grotendorst GR (1996) Stimulation of fibroblast cell growth, matrix production, and granulation tissue formation by connective tissue growth factor. J Invest Dermatol 107:404-411

45. Yokoi H, Sugawara A, Mukoyama M et al (2001) Role of connective tissue growth factor in profibrotic action of transforming growth factor-beta: a potential target for preventing renal fibrosis. Am J Kidney Dis 38:S134-S138

46. Quan T, He T, Kang S, Voorhees JJ, Fisher GJ (2002) Connective tissue growth factor: expression in human skin in vivo and inhibition by ultraviolet irradiation. J Invest Dermatol 118:402408

47. Nowinski D, Hoijer P, Engstrand T, Rubin K, Gerdin B, Ivarsson M (2002) Keratinocytes inhibit expression of connective tissue growth factor in fibroblasts in vitro by an interleukin-1alphadependent mechanism. J Invest Dermatol 119:449-455

48. Liu LD, Shi HJ, Jiang L et al (2007) The repairing effect of a recombinant human connective-tissue growth factor in a burnwounded rhesus-monkey (Macaca mulatta) model. Biotechnol Appl Biochem 47:105-112

49. Cicha I, Yilmaz A, Klein M et al (2005) Connective tissue growth factor is overexpressed in complicated atherosclerotic plaques and induces mononuclear cell chemotaxis in vitro. Arterioscler Thromb Vasc Biol 25:1008-1013

50. Twigg SM, Cooper ME (2004) The time has come to target connective tissue growth factor in diabetic complications. Diabetologia 47:965-968 